\section{PRIMENA KOMUNIKACIJE U DOMENU VIDLJIVE SVETLOSTI U OKVIRU INTELIGENTNIH TRANSPORTNIH SISTEMA}

Prof. dr Aleksandra Kostić-Ljubisavljević, dis

Univerzitet u Beogradu - Saobraćajni fakultet, a.kostic@sf.bg.ac.rs

Branka Mikavica, dis

Univerzitet u Beogradu - Saobraćajni fakultet, b.mikavica@sf.bg.ac.rs

\section{DOI: $10.31075 /$ PIS.64.02.03}

Stručni rad

Rezime: Razvojem Light Emitting Diodes - LED, komunikacija u domenu vidljive svetlosti, Visible Light Communication - VLC, postaje alternativa postojećim bežičnim tehnologijama. Integracija sistema koji rade u domenu vidljive svetlosti sa Inteligentnim Transportnim Sistemima može značajno unaprediti mnoge sfere saobraćaja i transporta, naročito $u$ domenu bezbednosti. Upotreba nelicenciranog opsega i šira implementacija VLC LED rasvete, kako u infrastrukturu, tako i u vozila, predstavljaju osnove za obezbeđivanje energetski efikasnog prenosa podataka dovoljno velikih protoka uz niske troškove. lako postoji veliki broj prednosti VLC tehnologije u poređenju sa ostalim tehnologijama, primena sistema zasnovanih na komunikaciji putem vidljive svetlosti još uvek je u početnoj fazi razvoja. Aplikacije koje omogućavaju prenos podataka između vozila (V2V) i između vozila i infrastrukture (V2l) imaju zahteve za koje se očekuje da će ih VLC adekvatno obezbediti u skorijoj budućnosti.

Ključne reči: $V L C, L E D$, ITS

\section{APPLICATION OF COMMUNICATION IN THE DOMAIN OF VISIBLE LIGHT IN THE FRAMEWORK INTELLIGENT TRANSPORT SYSTEMS}

\author{
Aleksandra Kostić-Ljubisavljević, Ph.D.T.E \\ University of Belgrade, Faculty of Transport \& Traffic Engineering \\ a.kostic@sf.bg.ac.rs
}

\section{Branka Mikavica, , M.Sc.T.E}

University of Belgrade, Faculty of Transport \& Traffic Engineering b.mikavica@sf.bg.ac.rs

Professional paper

Summary: Developing Light Emitting Diodes - LED, communication in the visible light domain, Visible Light Communication - VLC, becomes an alternative to existing wireless technologies. Integration of systems working in the visible light domain with Intelligent Transport Systems can significantly improve many spheres of transport and transportation, especially in the field of security. The use of unlicensed bandwidth and wider implementation of VLC LED lighting, both in the infrastructure and in vehicles, provide the basis for ensuring energy efficient data transmission with sufficiently large flows at low cost. Although there are a number of advantages of VLC technology compared to other technologies, the application of systems based on communication through visible light is still at an early stage of development. Applications that allow data transfer between vehicles (V2V) and between vehicles and infrastructure (V2I) have requirements that are expected to be adequately secured by VLC in the near future.

Key words: VLC, LED, ITS

\section{UVOD}

Sistemi za komunikaciju u domenu vidljive svetlosti, Visible Light Communication (VLC) sistemi, su bežični komunikacioni sistemi u razvoju, koji za prenos podataka koriste vidljivi deo spektra talasne dužine od $375 \mathrm{~nm}$ do $750 \mathrm{~nm}$. S obzirom da je radio spektar ograničen resurs, VLC postaje nova tehnologija za prenos koja predstavlja adekvatnu dopunu RF spektru [1].

Osnovna prednost VLC sistema je ta što je omogućena nadogradnja i upotreba postojeće infrastrukture, tako da se ovi sistemi istovremeno mogu koristiti i kao komunikacioni sistem i kao sistem za osvetljavanje. Stoga, implementacija VLC sistema zahteva minimalne investicione troškove. Vidljiva svetlost je potpuno bezbedna po zdravlje, što takođe predstavlja veliku prednost VLC sistema. Otpornost na elektromagnetne smetnje omogućava primenu VLC sistema u slučajevima kada nije pogodna upotreba sistema koji koriste radio talase.

Najznačajniji izazov sa kojim se suočavaju ovi sistemi je uspostavljanje linije optičke vidljivosti između predajnika i prijemnika, naročito u slučaju mobilnosti uređaja ili prepreka koje se mogu javiti između predajnika i prijemnika a koje mogu dovesti do prekida prenosa podataka. Otežanom uspostavljanju linije optičke vidljivosti doprinosi i prirodno i veštačko svetlo, što dodaje šum i interferenciju u kanalu. Uslov za ostvarivanje linije optičke vidljivosti može biti od značaja za primene koje zahtevaju visok nivo bezbednosti prenosa podataka, $\mathrm{s}$ obzirom da ne postoji mogućnost prenosa kroz zidove. Na primenu VLC sistema u outdoor okruženju utiču i vremenski uslovi, kao što su: kiša, sneg, magla, itd.

Značajne novine u pogledu prenosa informacija o saobraćajnim tokovima u Inteligentnim Transportnim Sistemima (ITS) nastaju uvođenjem sistema za komunikaciju u domenu vidljive svetlosti. Za unapređenje performansi transportnih sistema, razvijeni su različiti modeli komunikacije između vozila i infrastrukture, kao i između samih vozila: vehicle-to-infrastructure (V2I), vehicle-to-vehicle (V2V) i infrastructure-to-vehicle (I2V) [1]. 
Ovaj rad je koncipiran na sledeći način. Nakon uvoda, u drugom delu rada predstavljene su neke osnovne karakteristike VLC tehnologije, arhitektura sistema i načini realizacije VLC linka. Mogućnosti primene VLC tehnologije u ITS-u analizirane su u trećem delu rada. Četvrti deo rada prikazuje izazove u pogledu buduće primene VLC sistema. Zaključna razmatranja data su na kraju rada.

\section{OSNOVNE KARAKTERISTIKE I ARHITEKTURA VLC SISTEMA}

S obzirom da VLC koristi nelicencirani deo spektra za prenos podataka, omogućen je oko hiljadu puta veći propusni opseg u poređenju sa drugim bežičnim tehnologijama uz značajno niže troškove. Propusni opseg koji VLC sistemi trenutno obezbeđuju su do nekoliko desetina $\mathrm{Gb} / \mathrm{s}$, sa potencijalom za dalji rast primenom Multiple Input Multiple Output (MIMO) tehnika. Ove karakteristike omogućavaju da VLC sistemi budu deo budućih $5 \mathrm{G}$ tehnologija. Ujedno, VLC sistemi su potpuno kompatibilni sa ostalim RF komunikacionim sistemima koji imaju veliku primenu u Inteligentnim transportnim sistemima. Jedan od osnovih ciljeva ITS je unapređenje bezbednosti u saobraćaju. Dedicated Short Range Communication (DSRC) se do sada smatralo tehnologijom pogodnom za te primene [2]. Ipak, u poređenju sa DSRC, VLC pokazuje brojne prednosti. Osnovne karakteristike obe tehnologije prikazane su u Tab. 1.

Zbog manjeg efekta prostiranja višestrukim putanjama, dizajn VLC predajnika je značajno jednostavniji u odnosu na RF predajnik. Takođe, LED svetla su već integrisana u vozila, dok RF sistemi iziskuju dodatne troškove za ugradnju opreme. RF sistemi imaju manju skalabilnost, naročito u slučaju većeg broja vozila u neposrednom okruženju. S druge strane, u slučaju VLC sistema samo vozila koja se nalaze u liniji optičke vidljivosti su podložna interferenciji. Za razliku od RF sistema, VLC sistemi za pozicioniranje mogu obezbediti tačnost na nivou metra zahvaljujući velikoj direktivnosti svetlosti. Pored toga, VLC sistemi garantuju veću bezbednost prenosa podataka, imajući $u$ vidu da potencijalni napadač mora biti u liniji optčke vidljivosti potencijalne žrtve, verovatnoća otkrivanja napadača se povećava.

Tabela 1.Poređenje osnovnih karakteristika VLC i RF (DSRC)

\begin{tabular}{|c|c|c|}
\hline Karakteristika & VLC & RF (DSRC) \\
\hline Scenario komunikacije & Tipično LOS & LOS i NLOS \\
\hline Domet & $\begin{array}{c}\text { Mali domet i vrlo } \\
\text { usmeren }\end{array}$ & $\begin{array}{c}\text { Dalji domet i najčešć } \\
\text { omnidirektivan }\end{array}$ \\
\hline Frekvencijski opseg & $400-790 \mathrm{THz}$ & $5.8-5.9 \mathrm{GHz}$ \\
\hline Licenciranje & Besplatno & Neophodno \\
\hline Troškovi & Niski & Visoki \\
\hline Mobilnost & Srednja & Visoka \\
\hline $\begin{array}{c}\text { Osetljivost na vremenske } \\
\text { uslove }\end{array}$ & Osetljivi & Robusni \\
\hline $\begin{array}{c}\text { Osetljivost na } \\
\text { ambijentalne šumove }\end{array}$ & Osetljivi & Neosetljivi \\
\hline
\end{tabular}

Primenom VLC sistema, moguće je takođe uspostaviti razmenu informacija između susednih vozila (V2V komunikacije) koristeći prednja, zadnja i stop svetla. U slučaju V2V, vozilo koje se nalazi ispred semafora prima informacije i prosleđuje in vozilima koja se nalaze iza preko stop svetala. Posmatrano iz ugla Vehicular Ad-Hoc Network (VANET), VLC može predstavljati mrežu za pristup. Oblasti primene V2V su iste kao i za RF, uključujući unapređenje bezbednosti u saobraćaju, efikasnosti tokova, lokalne servise i pristup Internetu. Jasno je da su ograničenja u pogledu kašnjenja i dometa pri prenosu informacija veća u situacijama koje su kritične sa aspekta bezbednosti u odnosu na neke druge tehnologije. Novija istraživanja pokazuju da se to može eliminisati upotrebom dodatne opreme.

Tipična arhitektura VLC sistema sastoji se od predajnog entiteta i prijemnog entiteta. Ovi entiteti mogu biti uređaji kao što su mobilni personalni uređaji, vozila i/ili uređaji javne rasvete. VLC predajnik je elektrooptički konvertor koji prenosi podatke putem vidljive svetlosti kao medijuma za prenos. Najveću primenu imaju LED, koje emituju svetlost koja se može modulisati na tako visokim učestanostima da na ljudsko oko ne utiče bilo kakva razlika u osvetljenju u odnosu na situaciju bez modulacije. Kao rezultat, VLC predajnici mogu se istovremeno koristiti i za osvetljavanje i za prenos podataka. VLC prijemnik može se sastojati od PIN diode, lavinske fotodiode (APD) ili Complementary Metal Oxide Semiconductor (CMOS) senzora koji prima podatke. Signal koji je prethodno modulisan u vidljivom spektru se tada (u prijemnom delu VLC linka) konvertuje u električne signale koji se mogu obraditi u demodulatoru/dekoderu [1].

Postoje tri osnovna načina realizacije VLC linka u zavisnosti od načina ostavrivanja veze između predajnika i prijemnika i to: sa direktnom linijom vidljivosti, sa indirektnom linijom vidljivosti i difuzno, kao što je prikazano na Slici 1 .
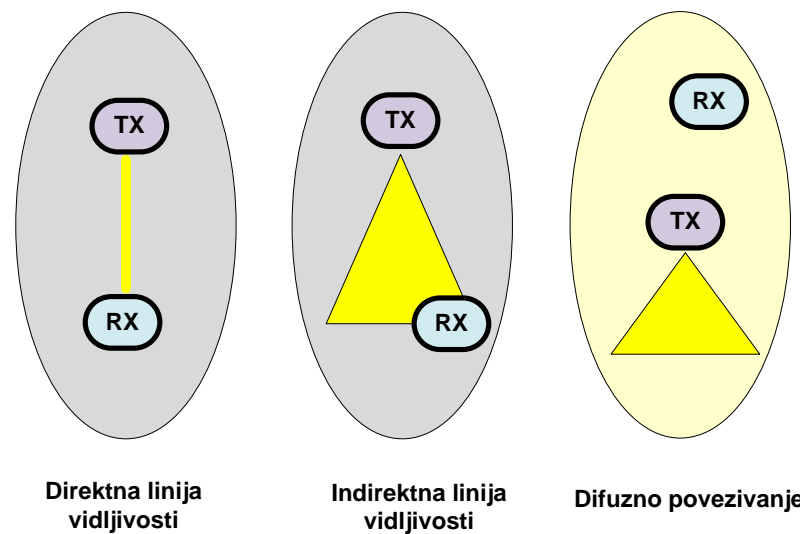

Slika 1. Moguće realizacije VLC linkova 
VLC sistemi kod kojih je ostvarena direktna linija vidljivosti imaju omogućen prijem signala najvećeg protoka na najdužim rastojanjima. Ove performanse se postižu na osnovu vrlo strogih zahteva u pogledu preciznog poravnanja. U slučaju indirektne linije vidljivosti, poravnanje je jednostavnije, ali nivo signala je na srednjem nivou. Osnovni nedostatak ovakve realizacije VLC linka je ostvarivanje kraćih rastojanja sa visokim ili srednjim vrednostima protoka. Difuzno povezivanje predajnika i prijemnika obezbeđuje najniže vrednosti protoka koji nema problema sa poravnanjem, ali je pogodan samo za upotrebu samo u indoor okruženju.

VLC je obećavajuća tehnologija u razvoju za čiju širu primenu je potrebno rešiti određene izazove kao što su: integracija VLC-a sa postojećim komunikacionim standardima, rešavanje interferencije usled postojanja ambijentalnog šuma, pitanja handover-a i interferencije između različitih VLC uređaja čiji broj sve više raste [3]. Standardizacija VLC sistema ima presudan značaj za prevazilaženje ovih izazova. VLC standardizacijom su se bavili Konzorcijum za komunikaciju putem vidljive svetlosti, Visible Light Communication Consortium (VLCC), u Japanu i Institute of Electrical and Electronics Engineers (IEEE). Japan Electronics and Information Technology Industries Association (JEITA) CP-1221, JEITA CP-1222 i JEITA CP-1223 standardi su objavljeni od strane VLCC [4]. Standard 802.15.7 je izdat od strane IEEE za fizički i MAC sloj. Cilj standarda je, između ostalog, obezbeđivanje pristupa opsegu širine nekoliko stotina $\mathrm{THz}$, neosetljivost na elektromagnetne smetnje, obezbeđivanje dodatnih servisa na osnovu postojeće infrastrukture za osvetljavanje, specifikacija Forward Error Correction (FEC) šema, obezbeđivanje mehanizama pristupa kanalu kao što su Contention Access Period (CAP) i ContentionFree Period (CFP) i specifikacija fizičkog sloja.

Modulacija signala u VLC razlikuje se od modulacija u RF komunikacionim sistemima usled amplitudskih i faznih karakteristika svetlosnog signala [5], pa se usled toga amplitudska i fazna modulacija ne mogu koristiti. U slučaju VLC sistema modulacija signala postiže se zahvaljujući varijacijama u intenzitetu svetlosti u zavisnosti od poruke. $U$ slučaju primene OOK [6-8], LED se isključuju i uključuju u skladu sa vrednošću bita koji se prenose. Na primer, 1 predstavlja stanje kada ima svetlosti, dok 0 predstavlja stanje sa smanjenim intenzitetom svetlosti. Osnovna prednost primene OOK je jednostavna implementacija, dok je osnovni nedostatak obezbeđivanje niskih protoka. U Tabeli 2 prikazano je poređenje sledećih impulsnih modulacija koje se koriste u VLC sistemima: Multipulse Pulse Width Modulation (MPPM), Expurgated Pulse Width Modulation (EPPM) i Multilevel Expurgated Pulse Width Modulation (MEPPM).
Tabela 2.Poređenje osnovnih karakteristika VLC i RF (DSRC)

\begin{tabular}{|c|c|c|c|}
\hline Karakteristika & $\begin{array}{c}\text { Modulacija } \\
\text { MPPM }\end{array}$ & $\begin{array}{c}\text { Modulacija } \\
\text { EPPM }\end{array}$ & $\begin{array}{c}\text { Modulacija } \\
\text { MEPPM }\end{array}$ \\
\hline $\begin{array}{c}\text { Podrška } \\
\text { efektu } \\
\text { zatamnjivanja }\end{array}$ & DA & DA & DA \\
\hline $\begin{array}{c}\text { Spektralna } \\
\text { efikasnost }\end{array}$ & $<1$ & $<1$ & $2-3$ \\
\hline Treperenje & Malo & Malo & Vrlo malo \\
\hline $\begin{array}{c}\text { Osetljivost na } \\
\text { LED } \\
\text { nelinearnosti }\end{array}$ & Malo & Malo & Malo \\
\hline
\end{tabular}

Color Shift Keying (CSK) modulaciona tehnika predložena je u IEEE 802.15.7 kako bi se povećao protok [9]. Modulacija se vrši na osnovu intenziteta tri boje u RGB LED izvoru, pri čemu se sve boje koje ljudsko oko može da razlikuje mapiraju u dva hromatografska parametra.

\section{PRIMENA VLC U V2I SEGMENTIMA ITS}

Prema European Telecommunications Standards Institute (ETSI), Inteligentni transportni sistemi su sistemi koji pružaju podršku transportu robe i putnika na osnovu informacionih i komunikacionih tehnologija u cilju efikasne i bezbedne upotrebe transportne infrastrukture i trasnportnih sredstava [10]. Osnovni cilj je unapređenje bezbednosti i efikasnosti transportnog sistema, ali i smanjenje emisije štetnih gasova. Termin ITS komunikacije, ITS communications (ITSC), označava sve komunikacione protokole, sisteme za upravljanje i dodatne funkcionalnosti [10]. ITS komunikacije predstavljaju novu vrstu komunikacionih sistema koji su namenjeni različitim transportnim scenarijima, kao što je prikazano na Slici 2.

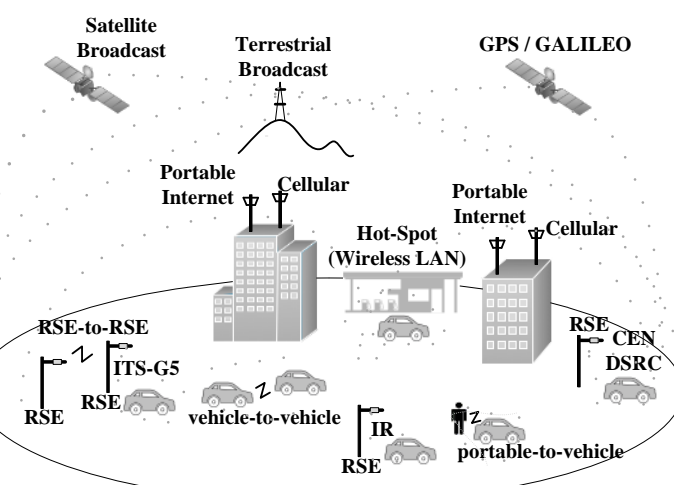

Slika 2. Ilustracija ITSC

Osnovni cilj ITS sistema je zadovoljenje potreba učesnika u saobraćaju, korisnika javnog prevoza i operatora u saobraćajnom sistemu uz minimiziranje iskorišćenih resursa. $\mathrm{Na}$ osnovu agregiranih podataka segment infrastrukture u ITS-u, kao i vozila, predviđaju buduće stanje u saobraćaju i donose odluke na lokalnom ili na globalnom nivou [11]. 
U budućim integrisanim ITS sistemima vozila će biti opremljena senzorskim, kognitivnim, komunikacionim funkcionalnostima, koje će između ostalog pružati podršku u odlučivanju [12]. Takva "pametna" vozila biće u mogućnosti da procenjuju stanje u saobraćaju u neposrednom okruženju, da prikupljaju podatke od javnog značaja (kao što je, na primer, zagađenje vazduha), ili da dobijaju podatke značajne za autonomno upravljanje datim vozilom $u$ realnom vremenu. Današnja vozila su opremljena velikim brojem senzora - preko 100, u zavisnosti od proizvođača i modela. Primeri senzora koji se koriste su: senzori za količinu kiseonika, senzor za položaj osovine, senzor za određivanje temperature itd. Svi ovi senzori šalju podatke ka Engine Control Units (ECUs), koji predstavljaju ugrađene sisteme koji kontrolišu jedan ili više električnih (pod)sistema u vozilu.

ITS aplikacije najčešće koriste bežične komunikacione sisteme između ITS stanica (vozila) i između mobilnih ITS stanica i fiksnih ITS stanica (infrastruktura kraj puta), sa jednim ili više hopova između izvorišnih i odredišnih ITS stanica. Takođe omogućavaju pristup javnim i privatnim (lokalnim) mrežama uključujući i pristup Internetu. ITSC se zasniva na dva domena: "ITS domenu" i "generičkom domenu". "ITS domen" odnosi se na sve elemente ITSC koji su specifični za ITS/ITSC standarde. "Generički domen" predstavlja druge elemente koji se koriste za ITS/ITSC. Podaci dostupni iz vozila i Road Side Units (RSU) mogu se slati lokalno u okviru geografski ograničene mreže ili do servera za centralnu obradu. Ovi podaci mogu se koristiti za detekciju događaja kao što su saobraćajne nezgode, radovi na putu, zagušenja u saobraćaju, približavanje vozila hitnih službi, itd. Takvi podaci se obrađuju u cilju pružanja podrške u vožnji konkretnom vozilu ili grupi vozila [13].

V2I sistemi omogućavaju komunikaciju između vozila i infrastrukture kraj puta. Najpre, poruke o uslovima u saobraćaju se u realnom vremenu bežično prikupljaju od strane infrastrukture. Nakon obrade podataka, obaveštenja o uslovima u saobraćaju u realnom vremenu prosleđuju se vozilima [14]. Ove komunikacione tehnologije imaju za cilj unapređenje bezbednosti u saobraćaju. Takođe, imaju veliki značaj u primenama koje se tiču mobilnosti vozila, u uslovima povećanja brzine vozila i unapređenja upravljanja saobraćajnim tokovima. Poznato je da su bežične komunikacije prepoznate kao najvažnija tehnologija koja pruža podršku ITS. Razvojem LED, VLC postaje alternativa postojećim bežičnim tehnologijama u ITS [15]. VLC sistemi zasnovani na LED mogu se primeniti u ITS-u koristeći postojeću saobraćajnu infrastrukturu, kao što su semafori sa LED svetlima. VLC sistemi ovogućavaju broadcast informacija vezanih na bezbednost u saobraćaju, čime se pruža podrška smanjenju broja saobraćajnih nezgoda i regulisanje saobraćajnih tokova.
Iz tog razloga, VLC predstavlja troškovno efikasno rešenje sa širokim područjem primene [16]. Ipak, treba napomenuti da u poređenju sa razvijenim RF tehnologijama, VLC je još uvek u početnoj fazi i potrebna su značajna unapređenja pre njegove šire primene u ITS [1].

Postoje dve vrste VLC baziranih V2I komunikacionih modela [17]. U prvom, ulična rasveta čiji primarni cilj jeste osvetljavanje, može biti upotrebljena za komunikaciju sa vozilima ili pešacima. Takav VLC model u opštem slučaju obezbeđuje pokrivenost od 50 - 100 m. Drugi model podrazumeva da se za komunikaciju koriste LED čija primarna funkcija nije osvetljavanje i koje su uvek u aktivnom stanju (čak i na dnevnoj svetlosti). Iz tog razloga, ovaj model je pogodan za unapređivanje bezbednosti $u$ saobraćaju. S druge strane LED koje se koriste za osvetljavanje su dostupne na ulicama i putevima čak i kada nema semafora, usled čega su pogodne za obezbeđivanje pristupa Internetu sa visokim protocima.

U VLC komunikacijama između vozila i infrastrukture koriste se dve vrste prijemnika, i fotodiode i senzori slike. Prijemnici zasnovani na fotodiodama su osetljivi na ambijentalne šumove. $\mathrm{Na}$ dnevnom svetlu, iluminacija Sunčeve svetlosti može dostići stotine hiljada luksa, što je značajno više od tipične LED koja se koristi u VLC primenama (1000 luksa). $\mathrm{U}$ poređenju sa fotodiodama, u slučaju postojanja različitih izvora svetlosti pri čemu je svaki signal različito modulisan, senzor slike ih može sve istovremeno prepoznati i ostvariti paralelni prenos podataka. Još jedna prednost senzora slike je da je otporniji na interferencije. Ipak, prijemnici zasnovani na fotodiodama omogućavaju više protoke sa nižim troškovima.

\subsection{Semafori kao deo VLC sistema}

Semafori i VLC sistemi u vozilima mogu biti sastavni deo ITS i imati značajnu ulogu u unapređivanju bezbednosti na putevima tako što će omogućiti vozilima koji imaju ugrađene VLC prijemnike blagovremen prenos informacija o uslovima $u$ saobraćaju, kao što je prikazano na Slici 3.

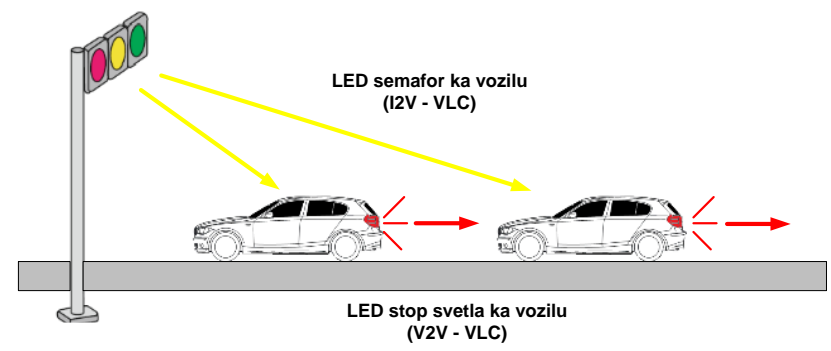

Slika 3. Primer I2V/V2V VLC komunikacija 
U izradi semafora postepeno se prelazi sa električnih sijalica ka LED osvetljenju. Razlog za to su brojne prednosti LED, kao što su energetska efikasnost, dugotrajnost, niski troškovi održavanja, bolja vidljivosti i manje zagrevanje. Uređaji u ovakvom sistemu rasvete mogu ujedno biti i predajnici, gde se signali prenose od rasvete koja je deo infrastrukture, dok su prijemnici ugrađeni u vozila (I2V komunikacije). RSU, kao što su semafori sa LED osvetljenjem pogodni su za broadcast informacija u I2V komunikacionim sistemima. Informacije o uslovima u saobraćaju mogu se kontinualno prenositi bez dodatne potrošnje energije, uz regulisanje saobraćajnih tokova, kao i smanjivanje broja saobraćajnih nezgoda. Pošto se svetlost prostire pravolinijski, moguće je uspostaviti vrlo usmerene komunikacije. Ovo je posebno pogodno u situacijama koje zahtevaju slanje informacija o uslovima u saobraćaju za svaku traku na putu.

\subsection{Pozicioniranje putem vidljive svetlosti}

Poznato je da Global Positioning System (GPS) ne pokazuje dobre performanse u zatvorenim prostorijama ili u urbanim sredinama, kada dolazi do interferencije prouzrokovane višestrukim putanjama i prekida linka zbog neposredne blizine velikog broja visokih zgrada. Sistem pozicioniranja na otvorenom putem vidljive svetlosti podrazumeva implementaciju LED semafora kao predajnika i primenu metoda procesiranja slike kako bi se odredila pozicija vozila. Ove metode zahtevaju korišćenje skupih kamera i kompleksnih procedura procesiranja slika, što je još uvek najveće ograničenje za široku primenu ove tehnologije. U slučaju pozicioniranja na osnovu pozicionih svetala, moguća je procena samo relativne lokacije vozila, što za veliki broj aplikacija ne pruža dovoljno precizne informacije. Sistem koji koristi dve fotodiode na strani prijema umesto highspeed kamera ima veću cenovnu efikasnost. Ovakav sistem sastoji se od semafora i dve fotodiode. Svetlost koju emituju svetla semafora sadrži informacije o poziciji. Dve fotodiode koje su postavljene na prednjoj strani vozila detektuju tu svetlost putem VLC linka. Pozicija vozila se određuje na osnovu primljenih informacija o poziciji semafora i razlike u vremenu prispeća signala do fotodioda. Ovaj sistem može imati i dva semafora, kada jedan može biti namenjen, na primer, vozačima, a drugi pešacima. Istraživanja pokazuju da se smanjenjem rastojanja značajno smanjuje preciznost sistema za pozicioniranje putem vidljive svetlosti kada se koristi samo jedan semafor. Degradacija performansi ovog sistema se naročito javlja na rastojanjima manjim od $20 \mathrm{~m}$. Pored toga, povećanje brzine vozila povećava i grešku pri pozicioniranju, čak i kada je vozilo udaljeno od semafora oko $50 \mathrm{~m}$. U slučaju primene dva semafora u sistemu za pozicioniranje, uočljiv je sličan trend degradacije performansi. Ovi rezultati su dobijeni u uslovima idealnog prenosa, uz dobru sinhronizaciju i odsustvo šuma na prijemu [18].

\subsection{Ostale primene VLC u ITS}

Nedavno je predložen sistem koji automatski podešava brzinu vozila na osnovu informacija o okruženju koje dobija od senzora na vozilu pod nazivom Adaptive Criuse Control (ACC) [2]. Jedna od najznačajnijih primena ovog sistema jeste povećanje kapaciteta saobraćajnica na osnovu smanjivanja rastojanja između vozila pod uslovom da se ne narušava bezbednost u saobraćaju. Međutim, pokazalo se da ovaj sistem ima ozbiljne nedostatke u vidu nepreciznosti, velikog kašnjenja i visoke cene. Kao rešenje za prevazilaženje ovih nedostataka, predložen je sistem Cooperative Adaptive Criuse Control (CACC), koji pored senzora koristi i V2V komunikacione linkove za prenos preciznih informacija od vozila koje prethodi datom vozilu [19]. Istraživanja pokazuju da CACC sistem opremljen VLC tehnologijom zadovoljava zahteve u pogledu brzine prenosa podataka i kašnjenja i omogućava precizno određivanje rastojanja između vozila čime se eliminiše potreba za naknadnom implementacijom skupih senzora u vozilo.

\subsubsection{VLC sistemi za upozoravanje učesnika u saobraćaju i prevenciju nezgoda}

Jedan od sistema koji su razvijen za potrebe upozoravanja i izbegavanja nezgoda je Collision Warning and Avoidance System (CWAS) [2]. Za implementaciju ovog sistema neophodno je da sva vozila koja učestvuju u saobraćaju budu opremljena VLC predajnicima i prijemnicima. Analizirajući podatke koje dobija od vozila iz svog okruženja, vozilo formira mapu koja sadrži relativne pozicije, pravce kretanja, trenutne brzine i ubrzanja svih vozila sa kojima ima uspostavljen direktan link. Ovaj sistem može se koristiti i za ranu detekciju sporih ili zaustavljenih vozila na putu ispred datog vozila. Nakon detekcije, sistem predviđa trajektorije detektovanih vozila u narednih nekoliko sekundi. Ukoliko se utvrdi velika verovatnoća da će se trajektorije posmatranog i detektovanog vozila u nekom trenutku ukrstiti, automatski se izdaje upozorenje vozaču da prilagodi upravljanje svojim vozilom kako bi se izbegla neželjena situacija. Za funkcionisanje ovog sistema neophodno je ispuniti sledeće zahteve: maksimalni domet mora biti $150 \mathrm{~m}$, maksimalno kašnjenje paketa je 100 ms a veličina paketa je 53 bajta [2]. Sistem koji funkcioniše na sličan način je Lane Change Assistance/Warning [2]. Ovaj sistem takođe formira mapu sa podacima o okolnim vozilima, uključujući i vozila u susednim trakama. Ukoliko u datom trenutku nije bezbedno izvršiti promenu trake, sistem obaveštava vozača o tome. Asistencija i upozoravanje prilikom promene traka zahteva izuzetno veliku preciznost koju GPS nije u mogućnosti da obezbedi, tako da je VLC tehnologija odlična alternativa za ovakvu vrstu sistema. Zahtevi ovog sistema su: maksimalni domet mora biti 150m, maksimalno kašnjenje paketa je $150 \mathrm{~ms}$ a veličina paketa je 36 bajta [2]. 


\subsubsection{Sistem za detekciju površine kolovoza}

Pored integracije LED $u$ formi prednjih svetala, pozicionih i stop svetla, LED nalazi primenu i kod svetla za maglu koja su najčešće postavljena u neposrednoj blizini kolovoza tako da vozači mogu jasno da uoče stanje kolovoza i graničnike. VLC tehnologija može se koristiti za detekciju površine kolovoza putem svetla za maglu, čime se vozač obaveštava o tome da li je kolovoz vlažan ili suv [20]. LED lampe osvetljavaju površinu kolovoza a fotodetektori primaju signal usled difuzne refleksije. Posebna pažnja mora se obratiti kada je kolovoz vlažan, s obzirom da je to jedan od najopasnijih stanja na kolovozu, najčešće kao posledica kiše. Kada svetlost obasja površinu, javlja se refleksija, prenos i absorpcija. Difuzna refleksija predstavlja refleksiju svetla od neravne površine, pa se upadni svetlosni zrak reflektuje iz mnogo uglova, za razliku od refleksije od ogledala. Najčešće se dešava kada upadno svetlo dolazi na neravnu površinu. Neki zraci se usled difuzne refleksije mogu vratiti nazad oko ugla upadnog zraka. Kada je kolovoz mokar, voda popunjava sitne neravnine na putu, čineći kolovoz glatkim što omogućava refleksiju nalik refleksiji od ogledala.

Ovim se minimizira difuzna refleksija. Pored toga, ako je nivo vode dovoljno dubok, dolazi do potpune unutrašnje refleksije unutar bare. Ukupna unutrašnja refleksija javlja se između dva različita medijuma fluida, kao što su vazduh i voda, usled različitih indeksa prelamanja. Kada dolazeći zrak svetlosti pređe površinu vode, dolazi do prelamanja zraka usled difuzne refleksije. Tada, za uglove koji su veći ili jednaki kritičnom uglu, difuzna refleksija će takođe reflektovati nazad u vodu usled ukupne unutrašnje refleksije. Rezultat toga je smanjenje uticaja zraka koji se ponovo reflektuju nazad do fotodetektora. $\mathrm{Na}$ taj način, sa povećanjem dubine vode na kolovozu, smanjuje se difuzna refleksija. To zapravo znači da se svaka promena nivoa vode može izmeriti. U sistemu predloženom u [20], svetla za maglu obasjavaju površinu kolovoza, dok se integracijom fotodetektora u okviru prednjih svetala postiže detekcija reflektovane svetlosti.

Eksperimentalno je utvrđeno da se za različite vlažnosti kolovoza, od suvog kolovoza do nivoa od 15 $\mathrm{mm}$ vode na kolovozu, primećuje svetlost različitih intenziteta. Najveći intenzitet svetlosti je izmeren kod suvog kolovoza, dok je najmanji u slučaju kada je nivo vode na kolovozu $15 \mathrm{~mm}$. Takođe, sa smanjenjem dubine vode na kolovozu, smanjuje se i trajanje impulsa, dok u slučaju previsokog nivoa vode ne dolazi do difuzne refleksije. Pored toga, utvrđeno je da se slanjem podataka na niskim frekvencijama povećava tačnost detekcije površine kolovoza pri naglim promenama kretanja vozila ili iznenadnim promenama nivoa vlažnosti kolovoza [20].

\section{IZAZOVI U BUDUĆOJ PRIMENI VLC SISTEMA}

Prenos putem vidljive svetlosti dosta zavisi od vremenskih uslova, pa može doći do velikih slabljenja u slučaju kiše, snega, a naročito magle. Pri pojavi magle, dolazi do smanjene vidljivosti, što čini VLC komunikaciju nepraktičnom, u nekim situacijama i nemogućom. Ovo je posledica same prirode magle, koja se sastoji od vodenih kapljica veoma male veličine. lako je prečnik vodenih kapljica reda veličine nekoliko stotina mikrona, imaju veliki uticaj na putanju svetlosti posredstvom apsorpcije, rasejanja i refleksije. U slučaju pojave magle na putu, vozač najčešće pali prednja svetla, svetla za maglu, ili oba. $\mathrm{U}$ istraživanju [21] analiziran je prenos podataka putem pozicionog svetla, kao i koeficijenti slabljenja za različite boje LED lampi.

Pokazalo se da je najmanje slabljenje pri korišćenju crvenih LED lampi u slučaju pojave magle, u poređenju sa zelenim i plavim. Ovo odgovara i boji pozicionog svetla koje je uglavnom crvene boje. Najveće slabljenje je prisutno kod plavih LED lampi. Sistem koji je predložen $u$ [21] sastoji se od predajnika koji emituje svetlost crvene boje posredstvom pozicionog svetla i LED sočiva, kao i prijemnika koji se sastoji od Frenelovog sočiva i tri fotodiode. LED sočiva na strani predaje prilagođavaju oblast vidljivosti LED svetla. $\mathrm{Na}$ strani prijema, svetlost se koncentriše ka fotodiodama pomoću Frenelovih sočiva. Veliki izazov predstavlja obezbeđivanje komunikacije između vozila u pokretu, pri uslovima magle na putu kada ne postoji direktna linija vidljivosti. Sistem predložen u [21] vrši detekciju u okviru prijemnika merenjem najveće vrednosti primljenog signala između tri fotodiode. Pretpostavlja se da su fotodiode pozicionirane u središnjem delu prednje strane vozila. $\mathrm{Na}$ ovaj način, Frenelovo sočivo fokusira svetlost na jednu od tri fotodiode, iako dolazi do premeštanja fokusa. Rezultati pokazuju da primena Frenelovih sočiva na prijemu u značajnoj meri utiče na održavanje odnosa signal-šum. Takođe, sa povećanjem gustine magle smanjuje se odnos signal-šum, ali u prihvatljivim vrednostima čak i kad je velika gustina magle.

VLC sistemi suočavaju se sa određenim tehničkim izazovima: relativna mobilnost u komunikaciji između vozila ili između vozila i infrastrukture može ometati liniju optičke vidljivosti; na VLC ogroman uticaj ima prirodno i veštačko svetlo, a pre svega Sunčeva svetlost koja povećava šum i interferenciju. Prvi izazov može se rešiti optimizacijom fiksnih i mobilnih svetala (na vozilima), dok se interferencija može minimizirati primenom optičkih filtara. Međutim, ovi izazovi značajno ograničavaju domete. Neki eksperimentalni rezultati pokazuju da je pouzdana komunikacija moguća kada se VLC predajnik i VLC prijemnik nalaze na udaljenosti manjoj od $40-50 \mathrm{~m}$ [22]. 
Pored ograničenja u pogledu propusnog opsega, aspekti kao što su modulacija signala, napajanje primopredajnika i višestruki pristup stvaraju poteškoće za širu implementaciju VLC. Ipak, prevazilaženje prethodno pomenutih izazova, komercijalizacija i standardizacija VLC sistema očekuje se u skoroj budućnosti.

\section{ZAKLJUČAK}

Ovaj rad predstavlja prikaz nekih mogućih primena komunikacije u domenu vidljive svetlosti za unapređenje preformansi Inteligentnih transportnih sistema. Savremeni transportni sistemi zahtevaju kontinuirano unapređivanje bezbednosti i efikasnosti. Pored pojedinačnih bezbednosnih mehanizama u samom vozilu, neophodno je razvijati složene sisteme koji doprinose unapređenju bezbednosti celog transportnog sistema.

Unapređenjem LED, čije su najznačajnije karakteristike energetska efikasnost, pouzdanost dug životni vek, komunikacija u domenu vidljive svetlosti pronalazi sve šire područje primene u ITS. Imajući u vidu da se LED sve više koriste u izradi semafora, ulične rasvete i saobraćajne signalizacije, VLC sistemi mogu se implementirati u Inteligentnim transportnim sistemima koristeći postojeću infrastrukturu. $\mathrm{Na}$ taj način ova tehnologija predstavlja obećavajuće, troškovno efikasno rešenje sa mogućnošću široke primene.

\section{Zahvale}

Ovaj rad je deo istraživanja u okviru projekta TR32025 Ministarstva prosvete, nauke i tehnološkog razvoja Republike Srbije.

\section{Literatura / References}

[1] Falcitelli, M.; Pagano, P. (2016). Visible Light Communication for Cooperative ITS, Intelligent Transportation Systems 52: 19-47.

[2] Yu, S. H.; Shih, O.; Tsai, H.-M.; Wisitpongphan, N.; Roberts, R. (2013). Smart automotive lighting for vehicle safety, IEEE Communications Magazine 51(12). 50-59.

[3] Khan, L. U. (2017). Visible light communication: applications, architecture, standardization and research challenges, Digital Communications and Networks 3(2017): 78-88.

[4] Hranilovic, S.; Lampe, L.; Hosur, S. (2013). Visible light communications: the road to standardization and commercialization (Part 1)[Guest Editorial], IEEE Communications Magazine 51(12): 24-25.

[5] Tsonev, D.; Videv, S.; Haas, H. (2014). Light fidelity (Li-Fi): towards all-optical networking. SPIE 9007, 90070.

[6] Zhao, Y.; Vongkulbhisal, J. (2013). Design of visible light communication receiver for on-off keying modulation by adaptive minimum-voltage cancelation, Engineering Journal 17 (4): $125-130$.
[7] Suban, A.; Prabu, P.; Manikandan, R.; Pradeep, M. (2013). Performance enhancement of data communication through visible light communication using on off keying, International Journal of Advanced Research in Computer Engineering and Technology 2(2): 559-563.

[8] Shinwasusin, E. a.; Charoenlarpnopparut, C.; Suksompong P.; Taparugssanagorn, A. (2015). Modulation performance for visible light communications. 6th International Conference of Information and Communication Technology for Embedded Systems (IC-ICTES), 1-4.

[9] IEEE. P802.15.7 - Standard for Short-Range Wireless Optical Communication. 2011.

[10]Intelligent Transport Systems (ITS). Communications Architecture- ETSI EN 302655 v.1.1.1. (2010).

[11]Sladkowski, A.; Pamula, W. (2016). Intelligent Transportation Systems - Problems and Perspectives, Springer Science+Business Media, $307 \mathrm{p}$.

[12]Picone, M.; Brusanelli, S.; Amoretti, M., Zanichelli, F., Ferrari, G. (2015). Advanced Technologies for Intelligent Transportation Systems, Springer Science+Business Media, $252 \mathrm{p}$.

[13]Kostic-Ljubisavljevic, A.; Radonjic Djogatovic, V.; Mikavica, B. (2017). Visible Light Communication as a Segment of the Intelligent Transportation System. Proceedings of the 6th International Conference Transport and Logistics, 211-214.

[14]Wang, W.; Bengler, K.; Jiang, X. (2018). Green Intelligent Transportation Systems. Proceedings of the 7th International Conference on Green Intelligent Transportation System and Safety. Springer Science+Business Media, $1037 \mathrm{p}$.

[15]Kostić-Ljubisavljević, A.; Mikavica, B. (2017). Komunikacija u domenu vidljive svetlosti kao deo Inteligentnih transportnih sistema. PosTel 2017: 161-170.

[16]Cailean, A.; Cagneau, B.; Chassagne, L.; Topsu, S.; Alayli, Y.; Dimian, M. (2013). Visible Light Communications Cooperative Architecture for the Intelligent Transportation System. Proceedings of the 20th International IEEE Symposium on Communications and Vehicular Technology in the Benelux SCVT, 1-5.

[17]Pathak, P. H.; Feng, X.; Hu, P.; Mohapatra, P.( 2015). Visible Light Communication, Networking and Sensing: A Survey, Potential and Challenges, IEEE Communications and Surveys and Tutorials 17(4): 2047-2077.

[18]Arnon, S. (2015). Visible Light Communication. Cambridge University Press. $224 \mathrm{p}$.

[19]Sjöberg, K.; Andres, P.; Buburuzan, T.; Brakemeier, A. (2017). Cooperative Intelligent Transport Systems in Europe Current Deployment Status and Outlook, IEEE Vehicular Technology Magazine 12(2): 89-97.

[20]Cahyadil, W.; Kim, Y.; Chung, Y.; Ghassemlooy, Z. (2015). Efficienat Road Surface Detection Using Visible Light, Proceedings of the 7th International Conference on Ubiquitous an Future Networks (ICUFN), 61-63.

[21]Kim, Y.; Cahyadi, W.; Chung, Y.( 2015). Experimental Demonstration of VLC-Based Vehicle-to-Vehicle Communications Under Fog Conditions, IEEE Photonics Journal 7(6): 7905309.

[22] Kumar, N.; Lourenco, N.; Terra, D.; Alves, L. N.; Aguiar, R. L. (2012). Visible Light Communications in Intelligent Transportation Systems, Proceedings of the Intelligent Vehicles Symposium, 748-753. 